\title{
Expressional Patterns of Adipocyte-Associated Molecules in the Rat Epididymal Fat during Postnatal Development Period
}

\author{
${ }_{\dagger}$ Ki-Ho Lee and Nan Hee Kim \\ Dept. of Biochemistry and Molecular Biology, College of Medicine, Eulji University, Daejeon 34824, Korea
}

\begin{abstract}
The adipogenesis is a maturation process of pre-adipocyte cell into mature lipid-filled adipocyte cell. The adipogenesis begins at the late prenatal stage and continues until the early postnatal age. Because the adipogenesis and formation of adipose tissue persist during postnatal period and are precisely regulated by the action of numerous gene products, the present research was attempted to determine the expressional patterns of adipose tissue-associated genes in the rat epididymal fat pad at different postnatal ages, from 7 days to 2 years of ages, using a quantitative real-time PCR analysis. The basal expression levels of CCAAT/enhancer binding protein gamma, sterol regulatory element binding transcription factor 1 , fatty acid binding protein 4, adiponectin, leptin, and resistin at the early postnatal ages were significantly lower than those at the elderly ages, even though a fluctuation of expressional levels was observed at some ages. The lowest expressional level of delta like non-canonical Notch ligand 1 was detected at 44 days and 5 months of ages. The expression of peroxisome proliferatoractivated receptor gamma (PPAR $\gamma$ ) was the highest at 44 days of age, followed by a diminished expression of PPAR $\gamma$ at the elderly ages. These results indicate the existence of a complex regulatory mechanism(s) for expression of adipose tissueassociated genes in the rat epididymal fat during postnatal period.
\end{abstract}

Key words : Epididymal fat, Postnatal development, Gene expression, Adipogenesis, Adipose

\section{INTRODUCTION}

Adipose tissue plays a variety of functional roles in our body and involves in the regulation of diverse physiological conditions, such as inflammation, atherogenesis, and even reproduction (Frühbeck, 2008). The formation of adipose tissue begins with a development of early fat cell, called pre-adipocyte, which is derived from precursor cells of mesenchymal origin (Pond, 1999). The differentiation of the precursor cell into pre-adipocyte appears in utero during prenatal development period, and the terminal differentiation of pre-adipocyte cell into mature adipocyte, called adipogenesis, occurs in the late prenatal period as well as the early postnatal age and continues throughout lifetime (Niemelä et al., 2008). The development of adipose tissue is an outcome of hyperplasic and hypertrophic growth of mature adipocytes and is differently appeared according to sex and age (Frühbeck, 2008).

The epididymal fat is considered as a type of gonadal adipose tissue, which is part of visceral fat depots (Berry et al., 2013; Frühbeck, 2008). The epididymal fat is localized between the testis and the head of epididymis and covers the entire efferent ductules. During postnatal development period, the size and weight of epididymal fat are tremen-

\footnotetext{
Manuscript received October 21, 2018, Received in revised form November 6, 2018, Accepted November 29, 2018

${ }^{\dagger}$ Corresponding Author : Ki-Ho Lee, Ph.D., Dept. of Biochemistry and Molecular Biology, Eulji University, Daejeon 34824, Korea. Tel: +82-42-2591643, Fax: +82-42-259-1649, E-mail: kiholee@eulji.ac.kr
}

This is an Open Access article distributed under the terms of the Creative Commons Attribution Non-Commercial License (http:// creative-commons.org/licenses/by-nc/3.0) which permits unrestricted non-commercial use, distribution, and reproduction in any medium, provided the original work is properly cited. 
dously increased due to expansion of fat cell number and size, even though it seems that a change of fat cell size gives more influence on the increase of epididymal fat weight after 80 days of postnatal age (Cleary et al., 1977). In addition to fat cell, an increase of a total weight of nonlipid filled cells in the epididymal fat pad, such as vascular cells, preadipocytes, and matrix cells, during postnatal period has also an effect on the change of epididymal fat weight (Cleary et al., 1977). Many researches have demonstrated that the change of epididymal fat weight is affected by intrinsic and/or extrinsic factors, including estrogen (Heine et al., 2000), high-fat diet (Kim \& Park, 2008), and genistein (Penza et al., 2006). These results indicate that an increase of epididymal fat mass during postnatal period could be under regulation of various internal and/or external components, even though detailed molecular mechanism on the development of epididymal fat tissue has not been suggested yet.

The conversion of pre-adipocyte cell into mature adipocyte cell requires the action of several transcription factors. For examples, CCAAT/enhancer binding protein $(\mathrm{C} /$ EBP) family, peroxisome proliferator-activated receptor (PPAR) $\gamma$, and sterol regulatory element binding transcription factor 1 (SREBP-1) are the early-acting factors to induce expression of adipocyte-specific genes (Niemelä et al., 2008). The procedure of adipogenesis is also precisely regulated by numerous anti-adipogenic and adipogenic factors. The well-recognized anti-adipogenic factors are leptin, testosterone, and growth hormones, while the major adipogenic factors include estrogen, $\operatorname{PPAR} \gamma$, and plasminogen activator inhibitor-1 (PAI-1) (Frühbeck, 2008). Some of factors involving in adipogenesis are synthesized and secreted by adipocytes, such as leptin (Frühbeck, 2008; Niemelä et al., 2008). Adiponectin and resistin are also representative substances released from adipose tissues, exhibiting several physiological functions (Frühbeck, 2008). In addition, expression of a transcription factor, preadipocyte factor-1 (PREF-1), is decreased during adipocyte dif- ferentiation into mature adipocyte (Niemelä et al., 2008). Thus, harmonious expressional regulation of a number of genes is required for proper development of mature adipocyte and formation of fat tissue. Some of researches have shown the expressional changes of genes in the epididymal adipocytes at different adult ages (Liu et al., 2011). However, the expression of genes associated with adipocyte differentiation and maturation for the formation of the epididymal fat tissue during postnatal period have not been examined in detail.

Thus, using quantitative real-time polymerase chain reaction analysis, the present research was focused to determine the presence and expressional patterns of some adipocyte-associated genes in the epididymal fat at different postnatal ages, from the neonatal age to the elderly age. The target molecules for the current study included some transcription factors and adipocyte-secreting molecules.

\section{MATERIALS AND METHODS}

\section{Experimental design and isolation of epididymal} fat pad

Male Spragure Dawley rats were used as an experimental model for the present research. A total of 7 experimental groups according to postnatal age, 7 days, 14 days, 24 days, 44 days, 5 months, 1 year, and 2 years old, were included. To obtain prepubertal male pups at 7, 14, and 24 days of age, pregnant female Spragure Dawley rats $(n=10)$ were purchased from Samtako (OSan, Korea) and individually separated. After the delivery, the neonatal rats at 7 days of age $(n=10)$, prepubertal rats at 14 days of age $(n=$ $10)$, and 24 days of age $(n=8)$ were obtained. Pubertal male rats at 44 days of age $(n=7)$ were acquired from Samtako (Osan, Korea). Adult and elderly male rats at 5 months $(n=5), 1$ year $(n=3)$, and 2 years $(n=3)$ of age were generously provided by Aging Tissue Bank (Department of Pharmacology, Pusan National University, Korea).

The animal was anesthetized by $\mathrm{CO}_{2}$ stunning in a 
closed chamber, and an incision was made on lower abdominal region to expose the reproductive tract. The intact epididymal part, including epididymal fat, was placed on cold-PBS containing dish. The epididymal fat was carefully separated from the epididymis and efferent ductules and quickly rinsed in fresh cold-PBS solution. The epididymal fat was then rapidly frozen in liquid nitrogen and stored in $-80^{\circ} \mathrm{C}$ until utilizing for total RNA isolation.

\section{Total RNA isolation and complementary DNA} (cDNA) construction

The homogenization of about 20-25 mg of the epididymal fat was carried out in $1 \mathrm{~mL}$ of easy-Blue total RNA extract solution (iNtRON Biotech, Sungnam, Korea). The addition of chloroform and isopropanol in sequence allowed for extraction of total RNA pellet, which was airdried and then resuspended in DEPC- $\mathrm{dH}_{2} \mathrm{O}$. The quantitative measurement of the total RNA was performed with a NanoDrop Lite spectrophotometry (Thermo Scientific, Wilmington, DE, USA), and the integrity and quality of the total RNA was checked by $2 \%$ agarose gel electrophoresis. The isolated total RNA was directly used for construction of cDNA by reverse transcription (RT) reaction.

One microgram of total RNA was used to carry out the RT reaction in ImProm-II ${ }^{\mathrm{TM}}$ reverse transcription system (Promega, Madison, USA). A final volume of $20 \mu \mathrm{L}$ of RT reaction mixture included oligo-dT primer, reverse transcriptase, $5 \mathrm{X}$ reaction buffer, and nuclease-free $\mathrm{dH}_{2} \mathrm{O}$. The RT reaction was performed in a condition of $25^{\circ} \mathrm{C}$ for $5 \mathrm{~min}$, followed by at $42^{\circ} \mathrm{C}$ for $90 \mathrm{~min}$ and then $70^{\circ} \mathrm{C}$ for $15 \mathrm{~min}$. Constructed cDNA was directly utilized for quantitative realtime PCR analysis of target genes in the epididymal fat.

\section{Analysis of quantitative real-time polymerase} chain reaction (PCR) and presentation of data

The primer was designed with Primer 3 software (http:// www.bioneer.co.kr/cgi-bin/primer/primer3.cgi: Whitehead Institute/MIT Center for Genomes Research, USA), and oligonucleotide primers used for real-time PCR analysis were listed in Table 1.

A mixture of $1 \mu \mathrm{L}$ of cDNA, $7 \mu \mathrm{L}$ of $\mathrm{iQ}^{\mathrm{TM}} \mathrm{SYBR}^{\circledR}$ Green Supermix (Bio-Rad Laboratories, Hercules, CA), 10 pmol of each primer, and DNase-free $\mathrm{dH}_{2} \mathrm{O}$ to make a final volume of $20 \mu \mathrm{L}$ was prepared to conduct quantitative real-time PCR. Using a thermocycler (Bio-Rad Laboratories), the PCR condition included a pre-denaturation step at $95^{\circ} \mathrm{C}$ for $5 \mathrm{~min}, 40$ cycles of a denaturation step at $95^{\circ} \mathrm{C}$ for $30 \mathrm{sec}$, an annealing step at $\mathrm{T}_{\mathrm{m}}$ for $30 \mathrm{sec}$, and an extension step at $72{ }^{\circ} \mathrm{C}$ for $30 \mathrm{sec}$. An addition of a final extension step at $72^{\circ} \mathrm{C}$ for 10 min was included at the end of each PCR. As a PCR internal control, $\beta$-actin (Actb) was also included. The PCR product was fractionated in $1.2 \%$ agarose gel to check the size as expected.

The expressional level of a specific target gene at a particular postnatal age was normalized with that of Actb to obtain a mean and a standard error derived from independently triplicated RT reactions and PCRs. The results were expressed as a relative ratio of transcript level of a target gene against $A c t b$. Statistical significance among the expression level of a target gene at different postnatal ages was determined by one-way ANOVA, followed by a posthoc analysis, Duncan's test. If $p$-value became less than 0.05 , it was considered as statistically significant between different age groups.

\section{RESULTS}

\section{Expressional pattern of Cebpg and Srebf1 in the} rat epididymal fat cells during postnatal development

Fig. 1 shows the expressional levels of Cebpg (A) and Srebfl (B) in the rat epididymal fat pad at different postnatal ages. The lowest expressional levels of Cebpg transcript were detected at 7 and 14 days of postnatal ages, followed by a significant increase of Cebpg mRNA level at 24 days of age (Fig. 1A). A great increase of Cebpg expression was observed at 44 days of age, but the transcript level of $\mathrm{Ce}$ - 
Table 1. Oligonucleotide primers for real-time PCR analysis

\begin{tabular}{|c|c|c|c|}
\hline Gene & Primer sequence $\left(5^{\prime} \rightarrow 3^{\prime}\right)$ & $\mathrm{T}_{\mathrm{m}}\left({ }^{\circ} \mathrm{C}\right)$ & PCR product size (bps) \\
\hline $\begin{array}{c}\text { Fabp4 } \\
\text { (NM_053365.1) }\end{array}$ & $\begin{array}{l}\text { (F) AGCGTAGAAGGGGACTTGGT } \\
\text { (R) ATGGTGGTCGACTTTCCATC }\end{array}$ & 60 & 185 \\
\hline $\begin{array}{c}\text { Srebf1 } \\
(\mathrm{NM}+001276708.1)\end{array}$ & $\begin{array}{l}\text { (F) GTGGTCTTCCAGAGGCTGAG } \\
\text { (R) GGGTGAGAGCCTTGAGACAG }\end{array}$ & 60 & 178 \\
\hline $\begin{array}{c}\text { Cebpg } \\
\text { (NM_012831.1) }\end{array}$ & $\begin{array}{l}\text { (F) CCACAGCCTTGTGACTTGAA } \\
\text { (R) CATTTCTGGGGAAGTGAGGA }\end{array}$ & 55 & 250 \\
\hline $\begin{array}{c}\text { Dlk1 } \\
\left(\mathrm{NM} \_012567\right)\end{array}$ & $\begin{array}{l}\text { (F) GGCCATCGTCTTTCTCAACA } \\
\text { (R) ATCCTCATCACCAGCCTCCT }\end{array}$ & 60 & 181 \\
\hline $\begin{array}{c}\text { Pparg } \\
(\mathrm{AB} 011365)\end{array}$ & $\begin{array}{l}\text { (F) CATTTCTGCTCCACACTATGAA } \\
\text { (R) CGGGAAGGACTTTATGTATGAG }\end{array}$ & 60 & 550 \\
\hline $\begin{array}{c}\text { Lep } \\
\left(\mathrm{NM} \_013076.3\right)\end{array}$ & $\begin{array}{l}\text { (F) TTCACACACGCAGTCGGTAT } \\
\text { (R) TGAGCTATCTGCAGCACGTT }\end{array}$ & 60 & 162 \\
\hline $\begin{array}{c}\text { Adipoq } \\
\text { (NM_144744.2) }\end{array}$ & $\begin{array}{l}\text { (F) AATCCTGCCCAGTCATGAAG } \\
\text { (R) TCCTGTCATTCCAGCATCTC }\end{array}$ & 60 & 229 \\
\hline $\begin{array}{c}\text { Retn } \\
\left(\mathrm{NM} \_144741.1\right)\end{array}$ & $\begin{array}{l}\text { (F) TGTCACTGTGTCCCATGGAT } \\
\text { (R) TAGTGACGGTTGTGCCTTCT }\end{array}$ & 60 & 156 \\
\hline $\begin{array}{c}A c t b \\
\text { (NM } 031144.3)\end{array}$ & $\begin{array}{l}\text { (F) ACCTTCAACACCCCAGCCATGTACG } \\
\text { (R) CTGATCCACATCTGCTGGAAGGTGG }\end{array}$ & 55 & 698 \\
\hline
\end{tabular}

Fabp4, fatty acid binding protein 4; Srebfl, sterol regulatory element binding transcription factor 1; Cebpg, CCAAT/ enhancer binding protein, gamma; Dlkl, delta like non-canonical Notch ligand 1; Pparg, peroxisome proliferatoractivated receptor, gamma; Lep, leptin; Adipoq, adiponectin; Retn, resistin; Actb, actin, beta.

bpg was transiently decreased at 5 months of age (Fig. 1A). The expressional levels of Cebpg at 1 year and 2 years of age were significantly higher than that at 5 months of age, but no different with that at 44 days of age (Fig. 1A).

The early reduction of Srebfl expression was detected at 14 days of age, compared with the transcript level of Srebfl at 7 days of age (Fig. 1B). There was no significant change of Srebfl transcript level at 24 days of age, while a surge of Srebfl expression in the epididymal fat pad was observed at 44 days of age (Fig. 1B). A significant drop, but still considerably higher than those at 14 days and 24 days of age, of Srebfl mRNA amount was detected at 5 months of age (Fig. 1B). The level of Srebfl transcript was significantly increased at two elderly ages, 1 year and 2 years of age, even though there was no significant difference in the expressional level of Srebfl between these two ages (Fig. 1B).

2. Expressional pattern of Dlk1 and Pparg in the rat epididymal fat cells during postnatal development

The highest level of Dlkl transcript was found at 7 days of age, followed by significant and steady drops of the transcript level until 44 days of age (Fig. 2A). There was no significant difference in the expressional level of $D l k l$ 
(A)

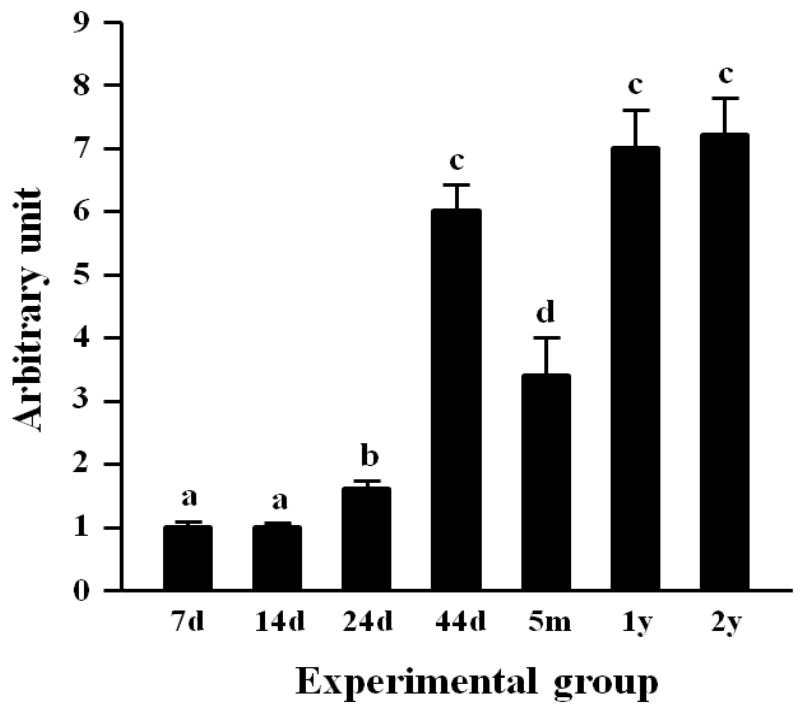

(B)

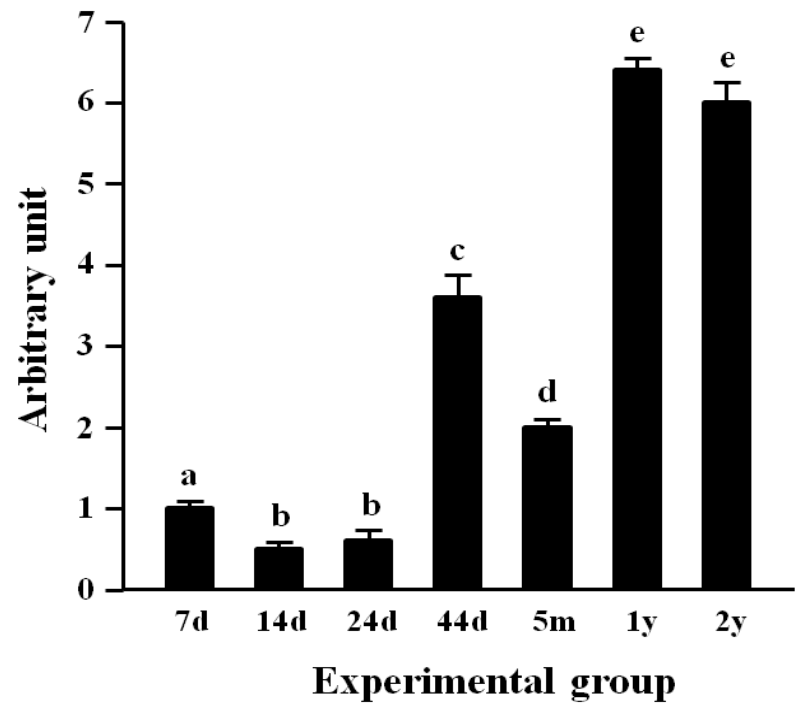

Fig. 1. Expressional patterns of Cebpg and Srebf1 in the rat epididymal fat during postnatal period. The relative expressional levels of Cebpg (A) and Srebfl (B) are shown here. Different letters indicate statistical significances at $p<0.05$. d, day; m, month; y, year.

between 44 days of age and 5 months of age (Fig. 2A). Over 100-folds increase of Dlkl mRNA level was observed at 1 year of age, compared with that at 5 months of

(A)

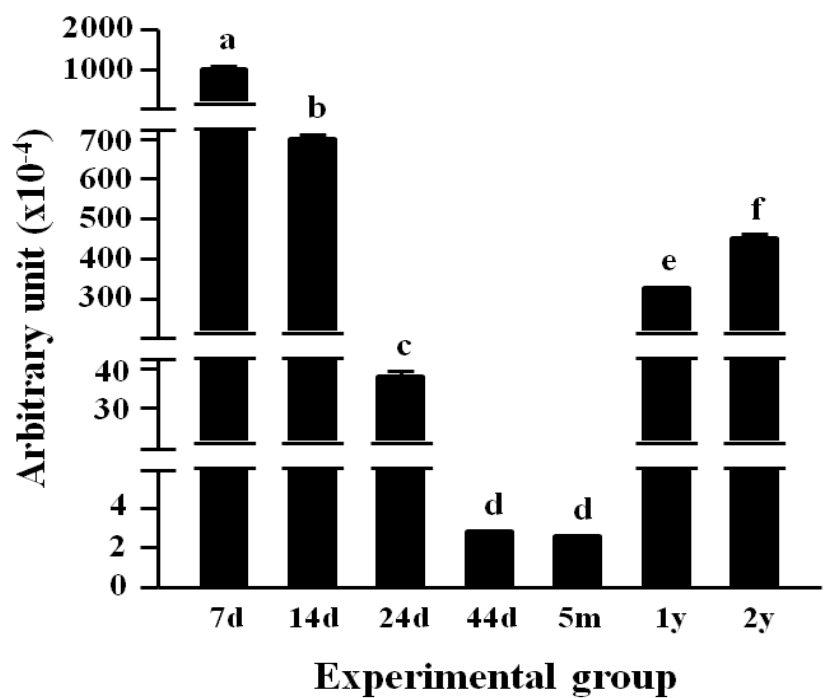

age (Fig. 2A). A further increase of Dlkl transcript level was detected at 2 years of age (Fig. 2A).

The expression of Pparg in the rat epididymal fat was

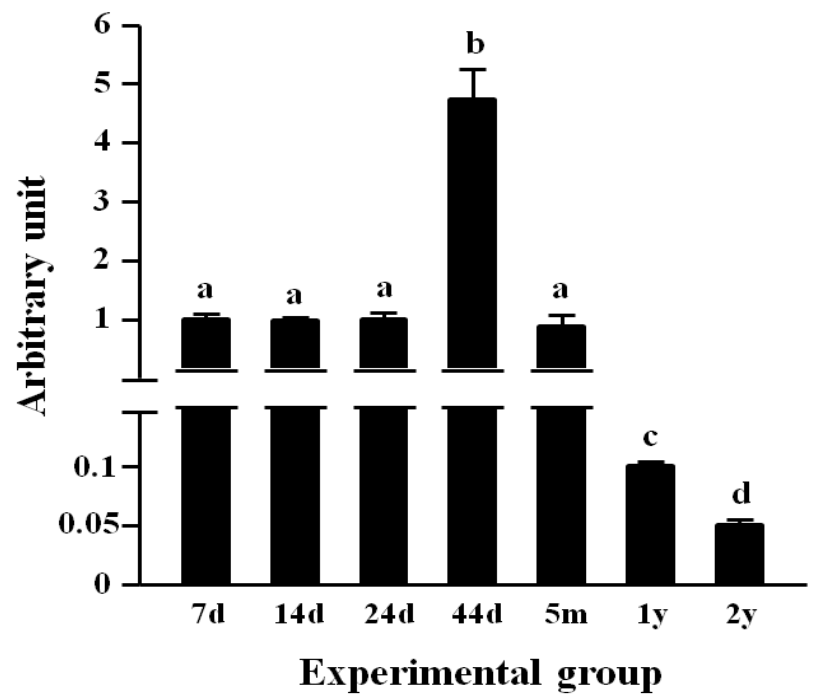

Fig. 2. Expressional patterns of Dlkl and Pparg in the rat epididymal fat during postnatal period. The relative expressional levels of Dlk1 (A) and Pparg (B) are shown here. Different letters indicate statistical significances at $p<0.05$. d, day; m, month; y, year. 
not significantly changed from 7 days of age to 24 days of age, even though a significant increase of Pparg transcript level was detected at 44 days of age (Fig. 2B). At 5 months of age, the level of Pparg transcript at the rat epididymal fat was not significantly different from those at 7,14 , and 24 days of ages (Fig. 2B). The expressional level of Pparg was further decreased at 1 year of age, followed by an additional significant drop at 2 years of age (Fig. 2B).

\section{Expressional pattern of Fabp4 and Adipoq in the} rat epididymal fat cells during postnatal development

The expressional level of Fabp4 in the epididymal fat at several postnatal ages is shown in Fig. 3A. The level of Fabp 4 transcript was significantly increased at 24 days of age, even though there was no significant difference in Fabp4 mRNA amount between 7 and 14 days of age (Fig. 3A). Another surge of Fabp4 expression was observed at 44 days of age, remaining at a steady state until 5 months of age (Fig. 3A). Over 10-folds increase of Fabp4 transcript level was found at 1 year of age (Fig. 3A). The level of Fabp4 transcript at 2 years of age was not significantly different from that at 1 year of age (Fig. 3A).

Fig. 3B shows the expression level of Adipoq expression in the epididymal fat during postnatal development. The expressional level of Adipoq was not significantly changed at 14 days of age, compared with that at 7 days of age (Fig. 3B). However, a significant increase of Adipoq expression was detected at 24 days of age, followed by a further huge rise of Adipoq transcript level at 44 days of age (Fig. 3B). Then, the level of Adipoq mRNA was significantly dropped at 5 months of age, even though the Adipoq transcript level at 1 year of age was returned to that of 44 days (Fig. 3B). An additional increase of Adipoq expression was observed at 2 years of age (Fig. 3B).

\section{Expressional pattern of Lep and Retn in the rat} epididymal fat cells during postnatal development

The expression of Lep in the rat epididymal fat at 7 days of age was the lowest among postnatal age groups, and the level of Lep at 14 days of age was not significantly differ-
(A)

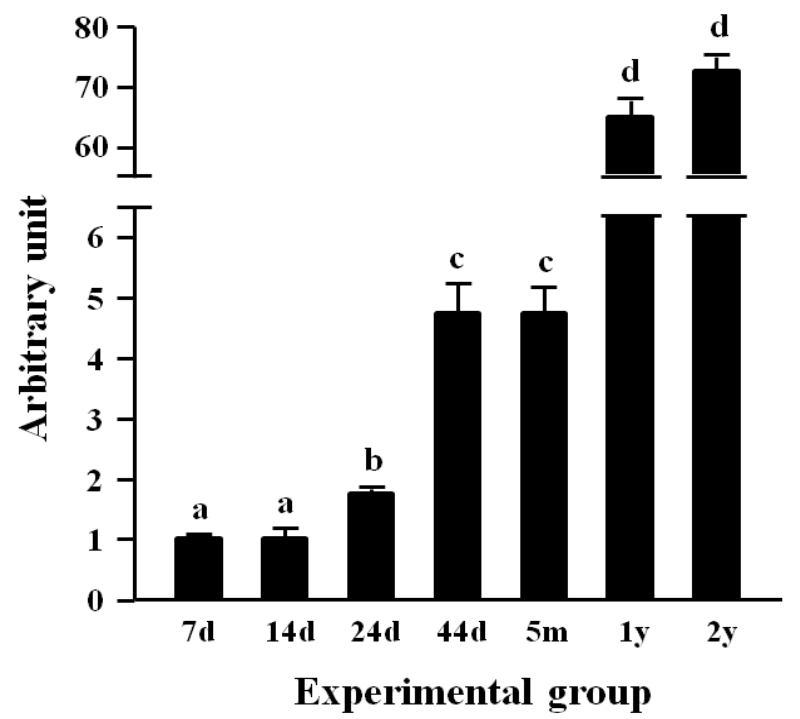

(B)

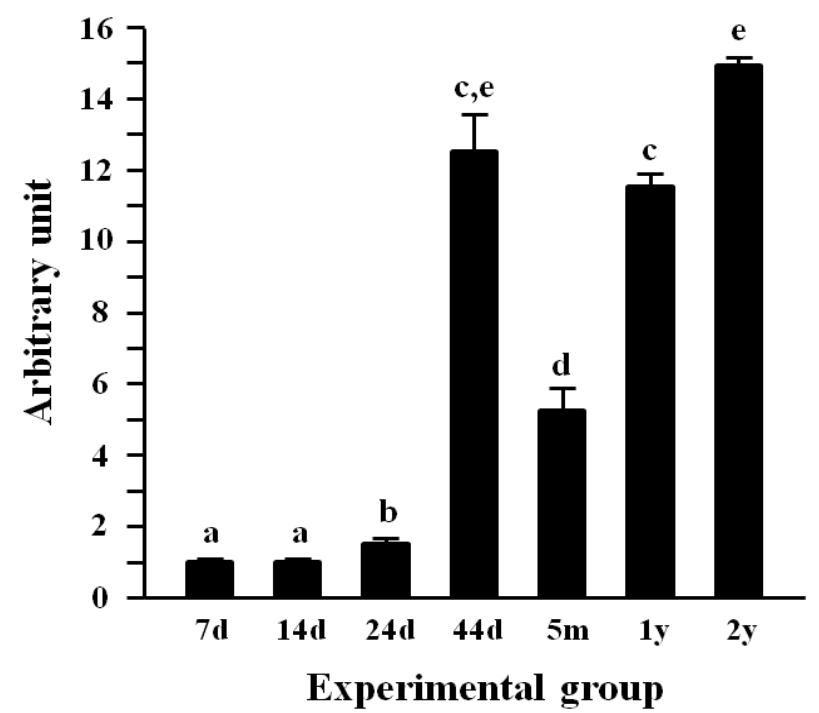

Fig. 3. Expressional patterns of Fabp4 and Adipoq in the rat epididymal fat during postnatal period. The relative expressional levels of Fabp4 (A) and Adipoq (B) are shown here. Different letters indicate statistical significances at $p<0.05$. d, day; m, month; $\mathrm{y}$, year. 
(A)

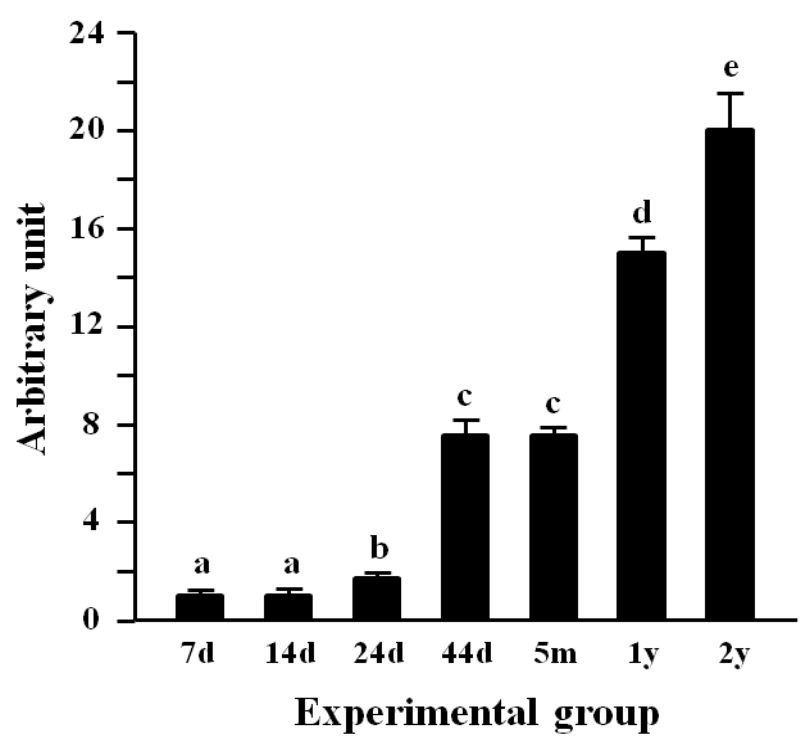

(B)

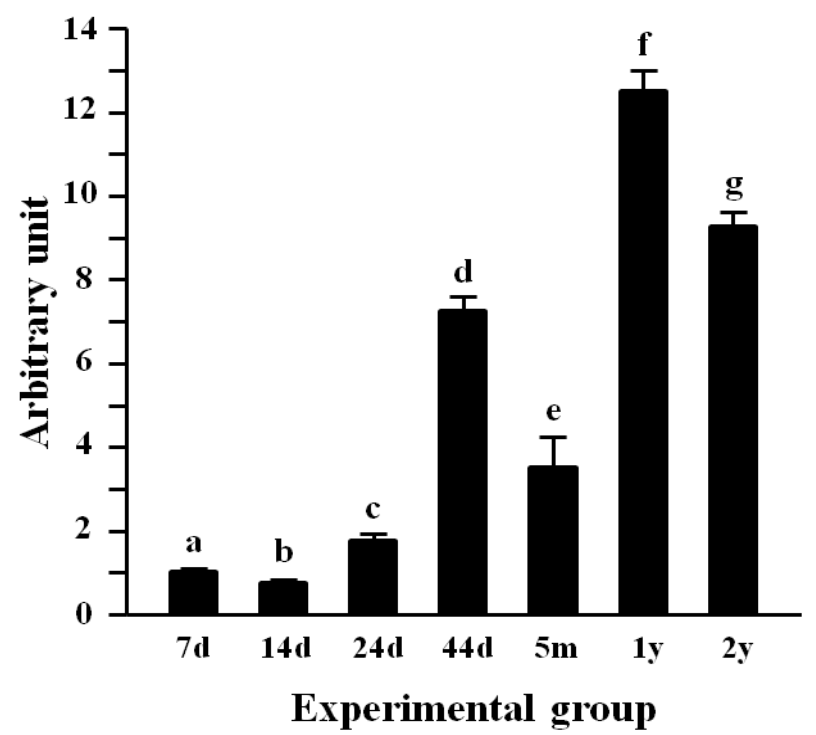

Fig. 4. Expressional patterns of Lep and Retn in the rat epididymal fat during postnatal period. The relative expressional levels of Lep (A) and Retn (B) are shown here. Different letters indicate statistical significances at $p<0.05$. d, day; m, month; y, year.

ent with that at 7 days of age (Fig. 4A). A significant increase of Lep mRNA level was first observed at 24 days of age, followed by a further increase of Lep transcript level at 44 days of age (Fig. 4A). There was no significant difference in the Lep mRNA amount between 44 days of age and 5 months of age (Fig. 4A). Compared with at 5 months of age, about 1-fold increase of Lep transcript level was detected at 1 year of age (Fig. 4A). At 2 years of age, the highest expression of Lep was observed in the rat epididymal fat among postnatal age groups (Fig. 4A).

The level of Retn transcript at 14 days of age was significantly lower than that at 7 days of age (Fig. 4B). But, the transcript level of Retn was transiently increased at 24 days of age (Fig. 4B). Over 2-folds increase of Retn mRNA amount was detected at 44 days of age, compared with that at 24 days of age (Fig. 4B). But, the expression of Retn was then significantly decreased at 5 months of age (Fig. 4B). The highest level of Retn transcript was observed at 1 year of age, followed by a significant decrease at 2 years of age (Fig. 4B).

\section{DISCUSSION}

The expressional patterns of adipocyte-related molecules in the rat epididymal fat tissue during postnatal period have been investigated in the present_research. Even though it is hard to address a conclusion to explain expressional patterns of all molecules examined, it is generally considered that expression levels of most adipocyte-related genes at the elderly age are likely higher than those at the early postnatal age.

It is relatively well defined that an expressional increase of Cebp family, including Cebpa, Cebpb, and Cebpd, is associated with the early event of adipogenesis occurring in pre-adipocyte cell (Niemala et al., 2008). Even though the expression of these Cebp family genes in the epididymal fat has been identified (Qian et al., 1998a), the presence of Cebpg in the epididymal fat has not been revealed. To our knowledge, the present research has demonstrated the expression of Cebpg transcript in the rat epididymal fat tissue for the first time. Even though, compared with its at 
44 days of age, a Cebpg mRNA level at 5 months of age becomes transiently decreased, it is thought that expression of Cebpg in the rat epididymal fat is gradually increased until pubertal age and remained at steady level for the rest of lifetime. Qian et al. (1998a) have demonstrated that expression of other Cebp family genes, including Cebpa, $C e b p b$, and Cebpd in the rat epididymal fat tissue is downregulated by leptin at young age, but not at old age. The present research shows a similar expression pattern of $\mathrm{Ce}$ bpg and Lep genes until 44 days of age. Thus, it is speculated that expression of Cebpg gene in the rat epididymal fat at young age could be regulated by leptin, like other Cebp family genes. Examination of expressional change of Cebpg gene in young rat epididymal fat with exogenous leptin treatment would provide a clear answer for the effect of leptin on expression of Cebpg gene.

The present research is the first report showing expressional patterns of Srebfl and Pparg genes_in the epididymal fat tissue throughout an entire postnatal period, even though the presence of transcripts of these two genes in the epididymal fat has been determined by other researches (Gallardo et al., 2007). As a pro-adipogenic transcription factor, Srebfl promotes early differentiation of pre-adipocyte by influencing expression of adipogenic genes (Kim \& Spiegelman, 1996). However, in the present study, it seems that the expression of Srebfl in the epididymal fat tissue during postnatal period is fluctuated and does not follow any pattern. Because the effect of Srebfl is more influential at the very early stage of adipocyte differentiation (Kim \& Spiegelman, 1996) and a number of preadipocyte in the rat epididymal fat pad becomes diminished as aged (Björntorp et al., 1979), it is speculated that Srebfl plays other roles in the epididymal fat tissue during postnatal development, instead of stimulating differentiation of pre-adipocyte. Because Srebf genes regulate lipid homeostasis in a cell (Eberlé et al., 2004), it is possible that Srebfl would involve in synthesis and/or metabolism of various types of lipid in the epididymal fat. Further re- searches would be necessary to reveal the functional role of Srebfl within the epididymal fat during postnatal period.

The expression of Pparg is required for adipogenic differentiation and for the maintenance of differentiated adipose tissue (Tamori et al., 2002). Qian et al. (1998b) have shown that the basal level of Pparg transcript in rat epididymal fat is higher at young age than old age, in agreement with our present findings. Because the epididymal fat weight in rat becomes increased as aging (Björntorp et al., 1979), it was expected that expressional level of Pparg with age also elevates and/or remains stable. However, the level of Pparg transcript at the old has tremendous reduced. In addition, an unanticipated observation has been detected with a transient surge of Pparg transcript level at 44 days of age, even the amount of Pparg transcript at the early postnatal ages relatively remains at steady level. Any reason showing such expressional pattern of Pparg in the epididymal fat tissue during postnatal development could not be provided at this point. But, it is proposed that expression of Pparg at certain level in the epididymal fat at old age is not required to maintain differentiated adipocyte, unlike at younger age. It is also suggested that conservation of the epididymal fat tissue at old age could be regulated by a distinct mechanism, different from that at young age.

The Fabp4, also known as_adipocyte protein 2, is mainly expressed in adipocyte tissue. The presence and expressional up-regulation by an insulin-sensitizing component of Fabp4 in epididymal fat have been determined by an earlier research (Kletzien et al., 1992). Because Fabp4 is known to promote lipid storage in adipocyte, it is reasonable to consider that expressional level of Fabp4 transcript would be increased as the fat weight becomes heavier. Indeed, our present findings have shown a gradual increase of Fabp 4 mRNA level until 5 months of age, followed by more than 10-folds surge at the old age. Together, these observations suggest that expression of Fabp4 might be related with the accumulation of lipid and regulation of 
insulin sensitivity in epididymal adipocyte cells. Future researches should be conducted to examine a detailed functional role of Fabp4 in the epididymal fat.

The adipose tissue secretes importatnt adipocytokines, including adiponectin, leptin, and resistin, which involve in the crosstalk between the adipocyte cell and other metabolic tissues to regulate systemic energy metabolism (Cao, 2014). Leptin provides a signal to hypothalamus to regulate the release of neuropeptides and neurotransmitters involving in control of food intake and energy expenditure (Cao, 2014). Adiponectin plays several important biological functions, such as improvement of insulin action and reduction of insulin resistance in obese condition, antiatherogenic activity, and cardioprotective effect (Cao, 2014). It is generally considered that resistin induces an increase of insulin-resistant state and contributes to the development of atherogenesis (Cao, 2014). Together, it is suggested that adipocytokines may play an important role in maintenance of metabolic homeostasis and prevention of various pathological outcomes caused by obesity. The expression of Lep, Adipoq, and Retn in the rat epididymal fat has been shown from a previous research (Puerta et al., 2002). However, expressional patterns of these molecules in the epididymal fat during postnatal period have not been determined until the present_research. Even though expression of Lep, Adipoq, and Retn in the rat epididymal fat during postnatal period do not simply follow a conclusive pattern,

it is collectively agreed that transcript levels of these three genes at young age are much lower than that at old age. In addition, a drastic increase of transcript level between 24 days and 44 days of ages would indicate an occurrence of significant change in the epididymal fat. In fact, significant increases of fat cell size and lipid accumulation have been observed around this postnatal period (Cleary et al., 1977). Thus, it is speculated that the abrupt changes of transcript levels of these three adipocytokine genes at 44 days of age could relate with significant growth of the epididymal adipocytes.

\section{ACKNOWLEDGEMENTS}

This research was supported by Basic Science Research Program through the National Research Foundation of Korea (NRF) funded by the Ministry of Education (2017R1D1A 1B03030209).

\section{REFERENCES}

Berry DC, Stenesen D, Zeve D, Graff JM (2013) the developmental origins of adipose tissue. Development 140:3939-3949.

Björntorp P, Karlsson M, Gustafsson L, Smith U, Sjöström L, Cigolini M, Storck G, Pettersson P (1979) Quantitation of different cells in the epididymal fat pad of the rat. J Lipid Res 20:97-106.

Cleary MP, Greenwood MRC, Brasel JA (1977) A multifactor analysis of growth in the rat epididymal fat pad. J Nutr 107:1969-1974.

Eberlé D, Hegarty B, Bossard P, Ferré P, Foufelle F (2004) SREBP transcription factors: Master regulators of lipid homeostasis. Biochimie 86:839-848.

Frühbeck G (2008) Overview of adipose tissue and its role in obesity and metabolic disorders. In: Yang K (ed), Methods in Molecular Biology, Adipose Tissue Protocols. 2nd ed. Vol. 456. Humana Press, Totowa, pp 1-22.

Gallardo N, Bonzón-Kulichenko E, Fernández-Agulló T, Moltó E, Gómez-Alonso S, Blanco P, Carrascosa JM, Ros M, Andrés A (2007) Tissue-specific effects of central leptin on the expression of genes involved in lipid metabolism in liver and white adipose tissue. Endocrinology 148:5604-5610.

Cao H (2014) Adipocytokines in obesity and metabolic disease. J Endocrinol 220:T47-T59.

Heine PA, Taylor JA, Iwamoto GA, Lubahn DB, Cooke PS (2000) Increased adipose tissue in male and female estrogen receptor- $\alpha$ knockout mice. Proc Natl Acad Sci USA 97:12729-12734. 
Kim YJ, Park T (2008) Genes are differentially expressed in the epididymal fat of rats rendered obese by a highfat diet. Nutr Res 28:414-422.

Kim JB, Spiegelman BM (1996) ADD1/SREBP1 promotes adipocyte differentiation and gene expression linked to fatty acid metabolism. Genes Dev 10:1096-1107.

Kletzien RF, Foellmi LA, Harris PK, Wyse BM, Clarke SD (1992) Adipocyte fatty acid-binding protein: Regulation of gene expression in vivo and in vitro by an insulin-sensitizing agent. Mol Pharmacol 42:558-562.

Liu LF, Shen WJ, Ueno M, Patel S, Kraemer FB (2011) Characterization of age-related gene expression profiling in bone marrow and epididymal adipocytes. BMC Genomics 12:212.

Niemalä S, Miettinen S, Sarkanen JR, Ashammakhi N (2008) Adipose tissue and adipocyte differentiation: Molecular and cellular aspects and tissue engineering applications. In: Ashammakhi N, Reis R, Chiellini F (ed), Topics in Tissue Engineering, Vol. 4, Oulu University, Finland, pp 1-26.

Penza M, Montani C, Romani A, Vignolini P, Pampaloni B, Tanini A, Brandi ML, Alonso-Magdalena P, Nadal A, Ottobrini L, Parolini O, Bignotti E, Calza S, Maggi A,
Grigolato PG, Di Lorenzo D (2006) Genistein affects adipose tissue deposition in a dose-dependent and gender-specific manner. Endocrinology 147:5740-5751.

Pond CM (1999) Physiological specialisation of adipose tissue. Prog Lipid Res 38:225-248.

Puerta M, Abelenda M, Rocha M, Trayhurn P (2002) Effect of acute cold exposure on the expression of the adiponectin, resistin and leptin genes in rat white and brown adipose tissues. Horm Metab Res 34:629-634.

Qian H, Hausman GJ, Compton MM, Azain MJ, Hartzell DL, Baile CA (1998a) Down-regulation of CCAAT/ enhancer binding proteins alpha, beta and delta in adipose tissue by intracerebroventricular leptin in rats. Biochim Biophys Acta Gene Struct Expr 1442:245-251.

Qian H, Hausman GJ, Compton MM, Azain MJ, Hartzell DL, Baile CA (1998b) Leptin regulation of peroxisome proliferator-activated receptor-gamma, tumor necrosis factor, and uncoupling protein-2 expression in adipose tissues. Biochem Biophys Res Commun 246:660-667.

Tamori Y, Masugi J, Nishino N, Kasuga M (2002) Role of peroxisome proliferator-activated receptor-gamma in maintenance of the characteristics of mature 3T3-L1 adipocytes. Diabetes 51:2045-2055. 